$$
\text { CONF.950905--52 }
$$

\title{
GA-A22209
}

\section{INTERPRETATION OF PISCES-A RF ANTENNA SYSTEM EXPERIMENTAL RESULTS}

\author{
by \\ D.A. ROTHWEIL, D.A. PHELPS, and R. DOERNER
}
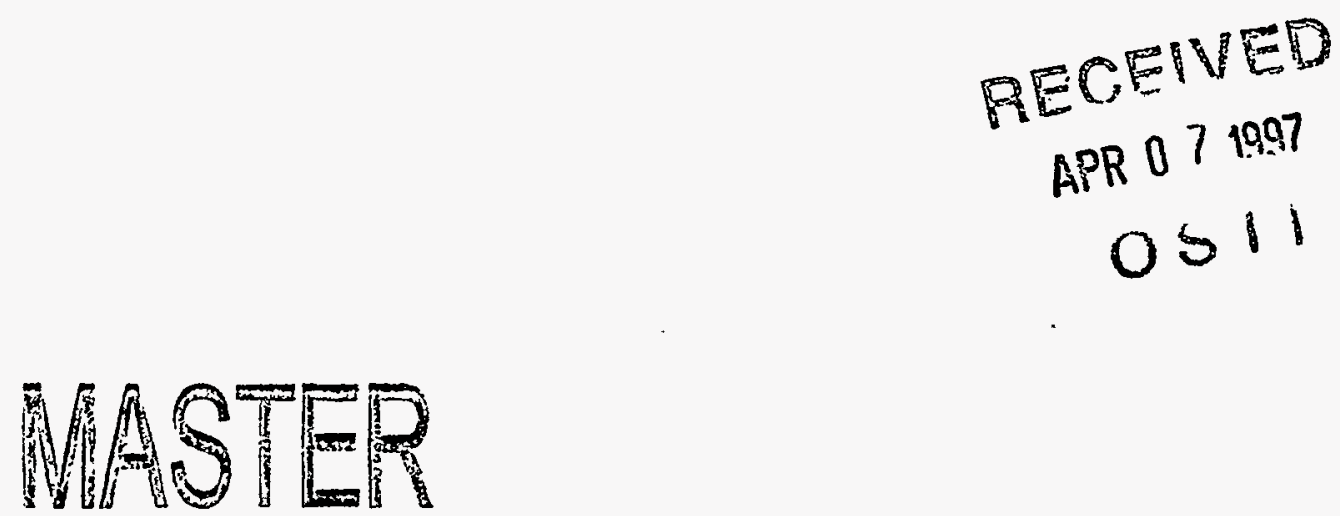

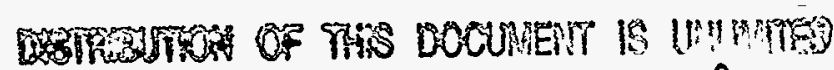

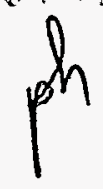

OCTOBER 1995 


\section{DISCLAIMER}

This report was prepared as an account of work sponsored by an agency of the United States Government. Neither the United States Government nor any agency thereof, nor any of their employees, makes any warranty, express or implied, or assumes any legal liability or responsibility for the accuracy, completeness, or usefulness of any information, apparatus, product, or process disclosed, or represents that its use would not infringe privately owned rights. Reference herein to any specific commercial product, process, or service by trade name, trademark, manufacturer, or otherwise, does not necessarily constitute or imply its endorsement, recommendation, or favoring by the United States Government or any agency thereof. The views and opinions of authors expressed herein do not necessarily state or reflect those of the United States Government or any agency thereof. 


\section{DISCLAIMER}

Portions of this document may be illegible in electronic image products. Images are produced from the best available original document. 


\section{INTERPRETATION OF PISCES-A RF ANTENNA SYSTEM EXPERIMENTAL RESULTS}

D.A. ROTHWEIL, D.A. PHELPS, and R. DOERNER*

This is a preprint of a paper presented at the 16th IEEE/NPSS Symposium on Fusion Engineering, September 30-October 5, 1995, Champaign, Illinois, and to be printed in the Proceedings.

*University of California, San Diego

Work supported by the U.S. Department of Energy under Contract No. DE-AC03-89ER51114

GA PROJECT 3466 OCTOBER 1995 


\title{
Interpretation of Pisces-A RFAntenna System Experimental Results*
}

\author{
D.A. Rothweil, ${ }^{a}$ D.A. Phelps, ${ }^{a}$ and R. Doerner ${ }^{b}$ \\ ${ }^{a} G e n e r a l$ Atomics, San Diego, California 92186-9784 \\ buniversity of Cálifornia, San Diego, California
}

\begin{abstract}
The paper describes experimental data from rf coupling experiments using one to four coil antenna arrays that encircle a linear magnetized plasma column. Experimental results using single turn coil that produce symmetric (i.e. $\mathrm{m}=0$ ), dipole $(m=1)$, and radial rf magnetic fields for coupling to ion waves are compared. By operating without a Faraday shield, it was observed for the first time that the plasma resistive load seen by these different antenna types tends to increase with the number of turns to at least the second power. A fourturn $m=0$ coil experienced a record $3-5 \Omega$ loading, corresponding to over $90 \%$ power coupling to the plasma. A four-turn $m=1$ coil experienced up to 1-1.5 $\Omega$ loading, also higher than previous observations. First time observations using a two coil array of $m=0$ coil are also reported. As predicted, the loading decreases with increasing phase between coil from $0^{\circ}$ to $180^{\circ}$. Experiments using four coil arrays were difficult to optimize and interpret primarily due to complexity of the manual tuning. To facilitate this optimization in the future, a proposed feedback control system that automatically matches load variations between 0.2 and $10 \Omega$ is described.
\end{abstract}

\section{INTRODUCTION}

Ion and electron heating of linear and toroidal magnetized plasma columns using rf antennas that partly or completely encircle the plasma has repeatedly captured the interest of the plasma community since the inception of fusion research. Currently, a new and unique antenna array and rf heating system is being developed for PISCES Upgrade [1]. This plasma processing device will produce a linear $9 \mathrm{~cm}$ diameter magnetized plasma column capable of $10^{13}$ to $10^{14} \mathrm{~cm}^{-3}$ plasma densities. To heat the plasma ions from $1-2 \mathrm{eV}$ to the desired $10-20 \mathrm{eV}$ the unidirectional launching of slow ion cyclotron waves against a magnetic beach [1-3] is being explored. This will create an ITER relevant plasma edge suitable for bombardment and survivability studies of tokamak first wall and divertor materials.

To determine the most efficient $\mathrm{rf}$ heating system for PISCES Upgrade, several different antenna coupling experiments in PISCES A $[1,2]$ are described. Next, experimental results are compared with theory and computer simulation. Finally, a feedback control system that covers sufficient range in loading (0.2-10 Ohms) and automatically tunes up to four coil arrays in several seconds is introduced.
The PISCES A plasma device is sketched in Fig. 1(a). A nominal $5 \mathrm{~cm}$ diameter plasma column of up to $5 \times$ $10^{12} \mathrm{~cm}^{-3}$ density is produced inside an evacuated drift tube. The axial magnetic field coil produce a $0.5-1.5 \mathrm{kG}$ magnetic field. This is suitable for launching ion cyclotron waves [3] using a $1.6 \mathrm{MHz}$ rf transmitter at $10-1000 \mathrm{~kW}$. A four coil antenna array is also sketched in Fig. 1(a) Each coil is a nominal $8 \mathrm{~cm}$ diameter two turn coil with a $1 \mathrm{~cm}$ pitch distance that encircles the plasma column. This coil is made of copper coated stainless steel wire (for rigidity at $500^{\circ} \mathrm{C}$ ) and produces an azimuthally symmetric rf magnetic field, i.e. $\cos (m \theta)$, where $m=0$. One to four turn coil of different diameters and pitch distances were studied. The $m=0$ coil were also compared with the single turn slot element [4] and one to four turn versions of the dipole, or $m=1$ coil [5] [Fig. 1(c)]. The diameters are all $8 \mathrm{~cm}$ and the pitch distance of the $\mathrm{m}=1$ coil element is $1 \mathrm{~cm}$. These conditions are optimum for operating as close to the plasma as practical and launching ion cyclotron waves at fixed $\mathrm{rf}$ frequency below the variable ion cyclotron frequency $[1,2]$.

\section{RF PLASMA COUPLING RESULTS}

Operation with and without a Faraday shield was explored. The shield was effectively a cylindrical array of axial shield bars located between the plasma and the coil. A water cooled limiter with a $5.5 \mathrm{~cm}$ diameter hole was used to protect the Faraday shield. To date, the strongest plasma coupling and widest range of plasma loading was achieved without a shield. Since this configuration best defines the potential limits required of the if matching circuit and feedback control system described later in this brief paper, we only discuss the results without a Faraday shield.

The experimental data for the most interesting single coil experiments studied are displayed in Fig. 2 . Note that the loading experienced by the single-turn slot, $m=0$ and $m=1$ coil elements are only a few tenths of an $\mathrm{Ohm}$ and result in low coupling efficiency. Stronger loading (i.e. several tenths of an Ohm) was achieved with single-turn coil elements using larger diameter plasma columns $[4,5]$. We could not increase the plasma diameter so we increased the number of turns. Up to $0.5-1 \Omega$ loading was achieved using a two-turn $\mathrm{m}=0$ coil element. This loading was similar regardless of the variation in coil diameter, pitch distance, or tilt angle (between the rf and applied magnetic field). The loading was further increased up to $3-5 \Omega$ using a four-turn $m=0$ coil element. The loading increases with the number of turns (n) to the power noted in Fig. 2 for measured data with $n \leq 4$.

\footnotetext{
*Work supported by the U.S. Department of Energy under Contract No. DE-AC03-89ER51114.
} 

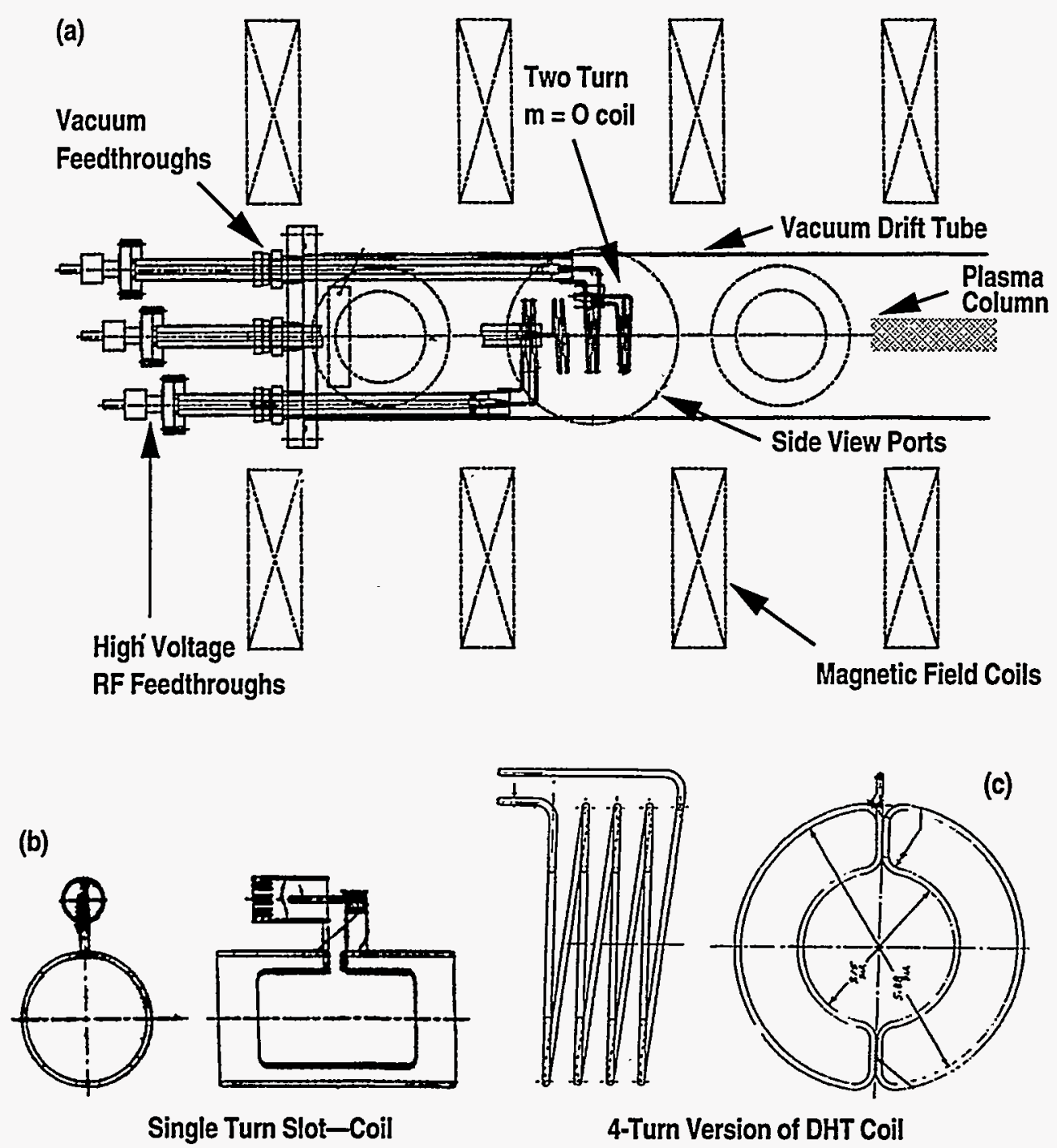

Fig. 1. Experimental configuration (a) cross section of the rf region, (b) single turn slot antenna, and (c) four-turn $\mathrm{m}=1$ coil element.

Two coil antenna array experiments were also performed. The 'phase between coils was varied and the loading measured. The loading was less for $180^{\circ}$ than for $0^{\circ}$ phase between coils. For $\pm 90^{\circ}$ phasing, the coils were unequally loaded. This is expected for a unidirectional phased array, because the mutual coupled power adds to one coil and subtracts from the other. This is desirable for heating plasma ions by launching slow ion cyclotron waves against a magnetic beach. MATLAB programs based on models of the antenna and rf system were developed to analyze this configuration. The results are shown in Table $I$ The results in Table I. Modified circuit parameters, $\left(\mathrm{C}_{1}, \mathrm{C}_{2}\right.$, and $\left.\mathrm{L}_{\mathrm{eq} 1}\right)$, closely match experimental settings for the observed plasma load. This is one example of many that shows excellent agreement between theory, computer simulation and experiment.

Experiments with four coil phased arrays were attempted, but the manual tuning of this antenna configuration was unwieldy. The MATLAB programs were used to assess the feasibility of designing an auto-tuning system, as described in detail in the last section.

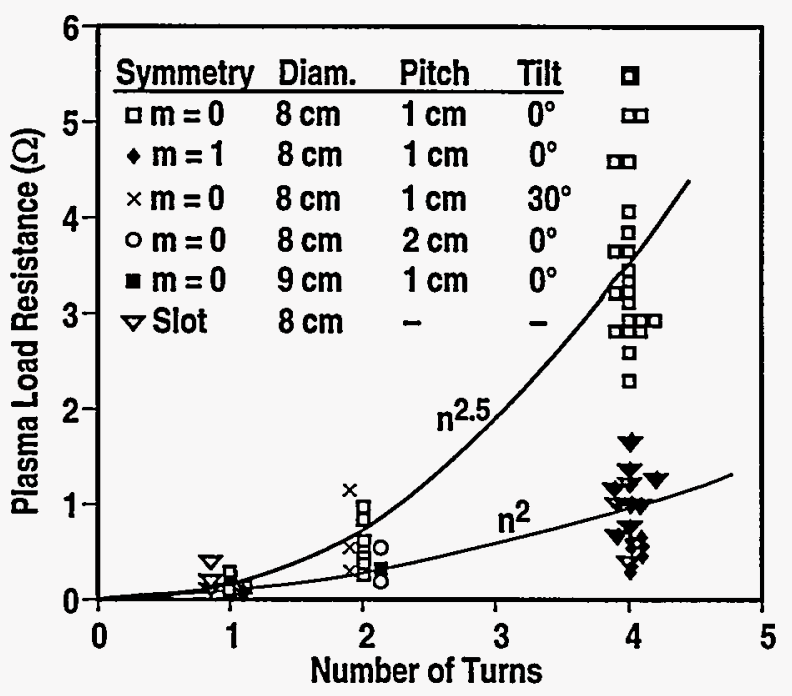

Fig. 2. Plasma loading as a functionof the number of turns on a col element for single coil experiments 
Table I

Coupled Power to $R_{p}, C_{1}, C_{2}, L_{e q}, R_{p}$

\begin{tabular}{|l|c|c|}
\hline & Coupled Power to. $\mathrm{R}_{\mathrm{p}}$ & $\mathrm{C}_{1}(\mathrm{~F})$ \\
\hline Experimental & $95 \%$ & $3.60 \times 10^{-10}$ \\
\hline MATLAB & $100 \%$ & $3.92 \times 10^{-10}$ \\
\hline PSPICE & $100 \%$ & $4.10 \times 10^{-10}$ \\
\hline & & \\
\hline $\mathrm{C}_{2}(\mathrm{~F})$ & $\mathrm{L}_{\text {eq } 1}=\mathrm{L}_{\mathrm{eq} 2}(\mathrm{H})$ & $\mathrm{R}_{\mathrm{p}}(\Omega)$ \\
\hline $3.07 \times 10^{-9}$ & $3.30 \times 10^{-6}$ & 0.825 \\
\hline $3.37 \times 10^{-9}$ & $3.30 \times 10^{-6}$ & 0.825 \\
\hline $3.06 \times 10^{-9}$ & $3.16 \times 10^{-6}$ & 0.825 \\
\hline
\end{tabular}

\section{EXPERIMENTAL CIRCUIT}

The rf circuit shown in Fig. 3 was used in the coupling experiments. This circuit drives a phased array comprised of two antenna coils represented by the inductances $L_{2}$ and $L_{4}$. The circuit can be reduced to drive one coil element $\left(L_{2}\right)$ or increased to drive four coil s. The power source is a $1 \mathrm{~kW}$, $1.6 \mathrm{MHz}, 50 \mathrm{Ohm}$ power supply.

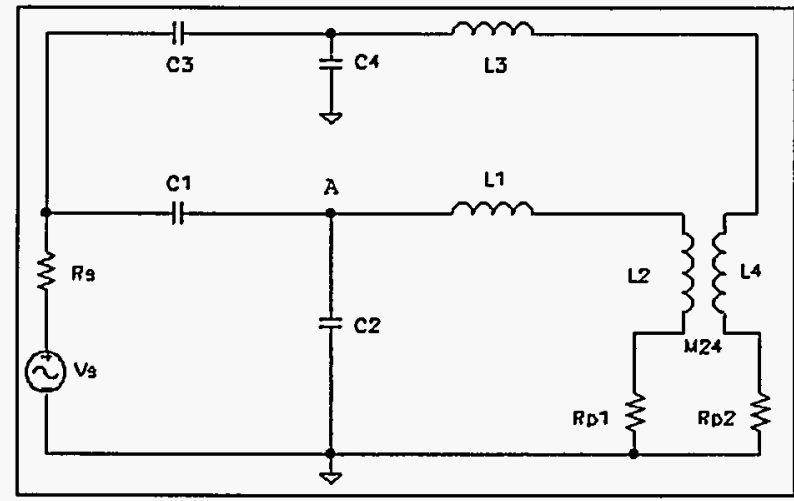

Legend

$R_{p 1,2}=$ Plasma load, seen by $L_{2}$ and $L_{4}$ respectively

$L_{\text {eq1,2 }}=L_{1}+L_{2}, L_{3}+L_{4}$

$L_{1,3}=$ Tunable inductors.

$L_{2,4}=$ The inductance of each experimental coil configuration.

$M_{24}=$ Mutual coupling between experimental coil configurations.

$\mathrm{C}_{1-4}=$ Tunable capacitors.

$R_{s}=$ Voltage source impedance $=50 \Omega$.

Fig. 3. PISCES-A experimental circuit

Analysis of the circuit for one antenna coil produces the following equivalent impedance $\left(Z_{e q}\right)$ at node $A$.

$$
Z_{e q}=\frac{R_{p 1}+j \omega\left[L_{e q}\left(1-\omega^{2} \cdot L_{e q} \cdot C_{2}\right)-C_{2} R_{p 1}\right]}{\left(1-\omega^{2} \cdot L_{e q} \cdot C_{2}\right)^{2}+\omega^{2} \cdot C_{2}^{2} \cdot R_{p 1}^{2}}
$$

In the PISCES-A experiments to date, the circuit values $\mathrm{L}_{\mathrm{eq}}$ and $\omega$ were held constant, while $C_{1}$ and $C_{2}$ were manually tuned to match the load to the $50 \Omega$ power supply. The real part of the load impedance at $A$ was set equal to the source resistance Rs:

$$
50=\frac{R_{p}}{1-2 \cdot \omega^{2} \cdot L_{e q} \cdot C_{2}+\omega^{4} \cdot L_{e q}^{2} \cdot C_{2}^{2}+\omega^{2} \cdot C_{2}^{2} \cdot R_{p}^{2}}
$$

Then, for a given plasma load $\left(R_{p}\right), C_{2}$ must satisfy:

$$
C_{2}^{2}\left(\omega^{4} L_{e q}^{2}+\omega^{2} R_{p}^{2}\right)-C_{2}\left(2 \omega^{2} L_{e q}\right)-\frac{50-R_{p}}{50}=0
$$

The remaining reactive component at $\mathrm{A}$ was then canceled by adjusting $C_{1}$ :

$$
C_{1}=\frac{1-2 \omega^{2} L_{e q} C_{2}+\omega^{4} L_{e q}^{2} C_{2}^{2}+\omega^{2} C_{2}^{2} R_{p}^{2}}{\omega^{2} C_{2} R_{p}-\omega^{2} L_{e q}\left(1-\omega^{2} L_{e q} C_{2}\right)} .
$$

$C_{1}$ and $C_{2}$ were computed from these equations, and the results were found to also be in agreement with a model using the circuit simulation code PSPICE and experiments for many of the antenna circuit configurations.

The network analysis programs were written in MATLAB and used to develop the capacitor tuning range characteristics for plasma loads from 0.2 to $10 \Omega$ displayed in Fig. 4 baked on the previous equations. These graphs are useful in determining the tuning range required for $C_{1}$ and $C_{2}$ can at a given frequency. They will be instrumental in developing an auto tuning system for $C_{1}$ and $C_{2}$ as described in the next section.

\section{FEED BACK CONTROL CIRCUIT}

Initial PISCES-A experiments required considerable time for tuning of the rf circuit, especially in configurations using four antenna coil elements. Automatic tuning capability will therefore be of great value for future experiments. An
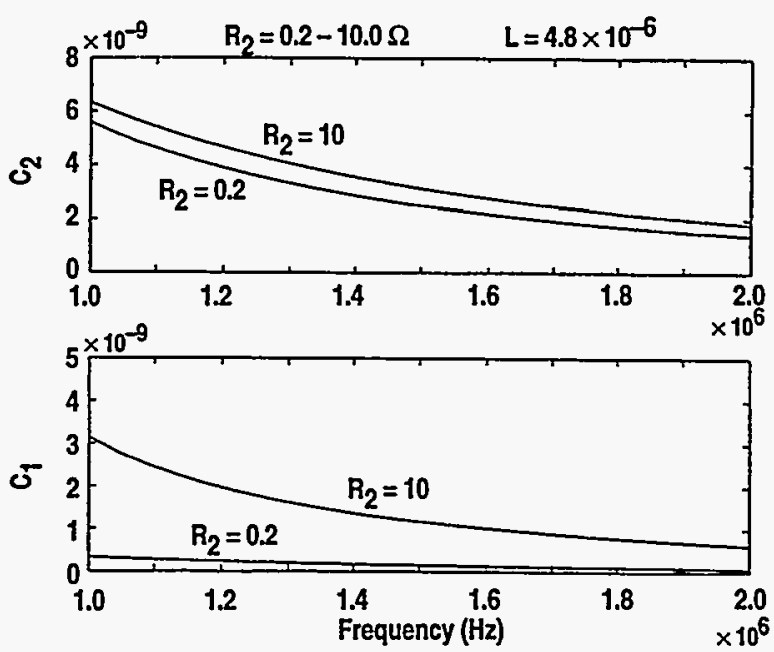

Fig. 4. Tuning curves for $C_{1}$ and $C_{2}$ 
automatic tuning system is envisioned using a computer interfaced with stepper motors attached to the tuning capacitors.

A possible control strategy would use $C_{2}$ to first tune the circuit for maximum power transfer. A feedback circuit would be used to determine the appropriate load voltage and current for this condition. $\mathrm{C}_{1}$ would then be used to minimize the phase shift between the power supply voltage and current. Other control strategies would be used to control the tuning of unique antenna configurations.

It is important that the controller for $C_{1}$ is faster than the control loop for $C_{2}$ in order to maintain a stable tuning system. The value of $\vec{C}_{1}$ varies by a factor of ten over the tuning range, and $C_{2}$ has a tuning range of a factor of three at 1.6 $\mathrm{MHz}$ which is the operating frequency of PISCES-A experiments.

The rf load characteristics can be compared with appropriate reference command signals to produce error signals. These error signals can then be used to drive power control circuits that drive stepper motors which in turn are varying $C_{1}$ and $\mathrm{C}_{2}$. Typically, a package system includes a stepper motor, and a stepper motor drive module. The envisioned drive module would communicate with its host computer via a RS232 communication port. Thus, the drive modules can easily be programmed to accept simple start and stop commands with programmable acceleration and deceleration time constants. The motor can also be commanded to move single step increments for fine tuning purposes.

\section{CONCLUSION}

For operation without a Faraday shield, observations have demonstrated that the plasma resistive load seen by these different antenna types tends to increase with the number of turns to at least the second power. The best loading was achieved with a four-turn $m=0$ coil. The observed 3-5 $\Omega$ loading was better than previously published $[1,3,4]$.
The agreement between theory, simulation and experiment was within $5 \%$. To date, results using four coil arrays have been inconclusive primarily due to the manual tuning complexity.

Scaling from the experimental data we predict that an eight turn $m=1$ coil will experience loading similar to the four turn $m=0$ coil in PISCES $A$. We recommend comparing both the $m=1$ and $m=0$ coil elements in the next series of PISCES A experiments in order to determine which produces better ion heating.

A concept for an automated feedback control system for matching the If circuit to the antenna array and load variations between 0.2 and $10 \mathrm{Ohms}$ has been introduced. This control system will significantly ease the experimental operation, and allow precise evaluation of the coupling efficiency of more complex antenna structures.

\section{ACKNOWLEDGMENTS}

It is a pleasure to acknowledge both Walter Ferguson and Will Carrig for their technical support on the presented control system that is proposed to automatically adjust the circuit capacitors.

\section{REFERENCES}

[1] R. Doerner, University of California at San Diego private communication (1993).

[2] D.A. Rothweil, et al., "Development of ICRF heating for PISCES-Upgrade," Bull. Am. Phys. Soc. 39, November 1994.

[3] T.H. Stix and, R.W. Palladino, "Experiments on ion cyclotron resonance," Phys. of Fluids 1, p. 446, 1958.

[4] S.N. Golovato, et al., "Plasma production and heating in a tandem mirror central cell by radio-frequency waves in the ion cyclotron frequency range," Phys. Fluids 31, December 1988.

[5] J.R. Ferron, J. Browning, R. Majeski, N. Hershkowitz, "Ion and electron heating in the Phaedrus-B central cell," Bull. Am. Phys. Soc. 32, October 1987. 